\title{
The Effect of Risk Context on the Value of a Statistical Life: a Bayesian Meta-model
}

\author{
Thijs Dekker • Roy Brouwer • Marjan Hofkes • \\ Klaus Moeltner
}

Accepted: 2 January 2011 / Published online: 26 January 2011

(C) The Author(s) 2011. This article is published with open access at Springerlink.com

\begin{abstract}
This paper presents the first value of statistical life (VSL) meta-analysis that empirically estimates correction factors for 'out of context' benefits transfer (BT) purposes. In the field of mortality risk reductions elicited willingness to pay values in one risk context, say road safety, are frequently applied in other risk contexts like air pollution. However, differences in risk perception and the population at risk across contexts are likely to result in diverging VSL estimates. In a meta-analysis of 26 international stated preference studies, a Bayesian model is estimated regressing contingent values for mortality risk reductions, originating from three different risk contexts, on the characteristics of the risk reduction itself and additional variables characterizing the underlying studies. A willingness to pay (WTP) premium for mortality risk reductions in the air pollution and general mortality risk context relative to improving road safety is observed. Evaluated at the mean, road safety VSL estimates should be multiplied by a factor 1.8 before being applicable in the air pollution context. Moreover, in an illustrative BT exercise we find limited overlap in the set of context specific predictive VSL distributions. Consequently, 'out of context' BT results in a substantial overor underestimation of the VSL.
\end{abstract}

Keywords Value of statistical life · Meta-analysis · Bayesian estimation · Mortality · Risk context

\section{Introduction}

Cost-effectiveness is usually an important reason to use previous research outcomes for new policy applications (Brouwer 2000). The fundamental problem underlying value transfers

T. Dekker $(\varangle) \cdot$ R. Brouwer · M. Hofkes Institute for Environmental Studies, VU University Amsterdam, De Boelelaan 1087, 1081 HV Amsterdam, The Netherlands e-mail: thijs.dekker@ivm.vu.nl

K. Moeltner

Department of Agricultural and Applied Economics, Virginia Tech, 208 Hutcheson Hall (0401), Blacksburg, VA 24061, USA 
(or benefits transfers (BT)) from one or more 'study site(s)' to a target 'policy site' is in assessing whether a given transfer is correct or not, while the 'true' value of the policy site is a-priori unknown. Emphasis has been placed upon the development and testing of alternative BT methods (e.g., Rosenberger and Stanly 2006; Johnston and Duke 2009). BT methods can be broadly categorized into two types (Navrud and Ready 2007). The simplest approach transfers mean values from study to policy sites. Such transfers are frequently used in practical decision making, but are dependent upon the pertinence of differences between transfer sites. The principal alternative is to use statistical techniques to estimate a value function from study site data. The multivariate 'value function transfer' approach assumes that the underlying utility relationship embodied in the parameters of the estimated model applies not only to the good itself and the individuals at the study site, but also to those at the policy site. While parameters are kept constant, the values of the explanatory variables to which they apply are allowed to vary in line with the conditions at the policy site. Traditionally, the construction of the value transfer function was based on a single source study. However, when the physical and temporal context differs between the source study and the policy site also functional BT can result in misleading welfare predictions. For this purpose meta-analytical regressions have been applied combining information from multiple source studies. By synthesizing information from a set of comparable studies a more robust transfer function can be estimated, resulting in more reliable benefit estimates. In addition, meta-analyses allow disentangling the effects of policy attributes, user characteristics, and methodological factors on welfare estimates (e.g. Moeltner et al. 2007).

BT practices in the field of mortality risk reduction often involve the transfer of 'out of context' values. That is, due to the limited availability of context specific values, values elicited for one risk source are applied in another risk context. For instance, the US Environmental Protection Agency (EPA) combines economic valuation studies on occupational and traffic related mortality risks to derive a value for prevented premature deaths in environmental contexts (US EPA 2000). The latter value for reductions in mortality risk, commonly referred to as the value of a statistical life (VSL), forms a significant share of the total benefits in many environmental programs (Alberini 2005). The psychology literature puts forward a number of arguments why willingness to pay (WTP) for risk reductions of similar size and therefore the VSL may differ between risk contexts (Slovic 1987). In particular, differences in risk perception and the population at risk across contexts are expected to result in diverging VSL estimates. Hence, not or arbitrarily adjusting VSL estimates in BT practices for the context in which values have been elicited may have serious implications for policy evaluation.

Reviews by Rowlatt et al. (1998) and Revesz (1999) propose adjustment factors for transferring VSL estimates from road safety to air pollution, based on context specific risk characteristics such as voluntariness, control and responsibility, and related age, latency and health status effects. Although both reviews predict a higher VSL in the air pollution context compared to road safety, empirical evidence of such a context effect is limited and mixed in primary valuation studies (e.g. Tsuge et al. 2005; Vassanadumrongdee and Matsuoka 2005). Consequently, the U.K. Health Department refrains from applying BT of VSL estimates from the road safety to the air pollution context (Dunn 2001). On the same grounds, the Science Advisory Board-Environmental Economics Advisory Committee advised the US EPA in the year 2000 not to adjust its default VSL value for risk and population characteristics, including context (Dockins et al. 2004). More recently, the US EPA commissioned a group of experts to review its approach to mortality risk valuation. The expert group questions the existence of a single VSL and considers meta-analysis an appropriate method to identify variations in VSL estimates across subpopulations, including risk context (Allen et al. 2006). 
This paper presents the first meta-analysis with the explicit aim of examining the effect of risk context on the VSL. Previous VSL meta-analyses that included control variables for risk context, focused primarily on variations in the VSL across countries (Elvik 1995; Miller 2000), sensitivity to scope effects (Takeuchi 2000) or merely provided an overview of the VSL stated preference literature (Braathen et al. 2009). None of the existing meta-analyses aimed at identifying correction factors for BT purposes. Accordingly, our paper adds to the literature by (i) identifying these correction factors and (ii) illustrating the consequences of not adjusting the VSL to the context of the policy application. Moreover, our Bayesian model allows us to filter out the effect of procedural variance in the underlying CV studies by making BT predictions unconditional upon methodological variables.

To this end we apply strict and mutually exclusive study and context selection criteria, such that the VSL can be contrasted directly across contexts. ${ }^{1}$ The mortality risk contexts considered in this paper are air pollution and road safety. A third set of "context free" studies is also included due to its prospective application in environmental policies and common survey design. Our study includes only contingent valuation (CV) studies, since risk context may be hard to categorize across jobs in hedonic wage (HW) studies, as collated in Viscusi and Aldy (2003) and Mrozek and Taylor (2002). Also the US EPA expert group for conducting meta-analysis regards derived estimates in $\mathrm{CV}$ and $\mathrm{HW}$ types of studies as distinctly different and suggests a separate analysis for both valuation methods (Allen et al. 2006). The main advantage of using CV studies only is that we use a single welfare measure compared to other meta-analyses that combined both study types (de Blaeij et al. 2003; Elvik 1995; Kochi et al. 2006; Miller 2000). Finally, WTP values for mortality risk reductions are analyzed in a Bayesian framework suitable for relatively small sample sizes (e.g. Moeltner and Woodward 2009).

The remainder of this paper is organized as follows. Section 2 discusses the theoretical foundations and available empirical evidence of the expected difference in WTP values between mortality risk contexts. Section 3 presents a description of the econometric model, followed in Section 4 by a presentation and discussion of the database. Section 5 presents the results of the Bayesian meta-model, while its implications for BT practices are discussed in Section 6. Finally, Section 7 concludes and provides recommendations for the use of VSL estimates in future policy analysis.

\section{VSL and Risk Context}

\subsection{Theoretical Foundations}

In cost-benefit analysis the concept of a VSL is used as a measure to identify the value of a randomly saved life. If a disease is expected to kill 10 out of every 100,000 people and preventive measures can be taken to reduce the probability of dying $q$ to 8 out of every 100,000 , then the VSL is calculated by dividing the maximum amount of money an individual is willing to pay (WTP) for this risk reduction by the change in probability $(\Delta \mathrm{q}=2 / 100,000)$. More formally, the VSL describes the rate at which people are willing to trade off income for reduc-

\footnotetext{
1 Takeuchi (2000) and Braathen et al. (2009) control for multiple risk contexts, including the environment and health. The latter context, however, concerns various types of diseases, which can be implicitly associated with environmental pollution.
} 
tions in mortality risk (Alberini and Chiabai 2007). Equation (1) describes this marginal rate of substitution and the approximation discussed above, where $V$ denotes expected utility, $q$ the probability of dying and $W$ current wealth.

$$
\mathrm{VSL}=\frac{\frac{\partial V}{\partial q}}{\frac{\partial V}{\partial W}} \approx \frac{\Delta W}{\Delta q}=\frac{W T P}{\Delta q}
$$

Trade-offs made by individuals between safety and wealth are implicitly guided by preferences and perceptions towards mortality risks. Slovic (1987) identifies four determinants of individual risk perception; (i) awareness and knowledge, (ii) severity, (iii) voluntariness and (iv) degree of control. An individual has to be aware of a risk before she can form a judgment about it. In the same vein, people tend to overestimate risks that receive a lot of media attention (Slovic 2000). Severity refers to the degree of harm experienced from a 'bad' outcome. The meta-analysis presented here covers a single risk consequence, i.e. mortality. Hereby, we keep the 'objective' measurement of severity constant across observations, enabling an empirical assessment of the effect of risk context on stated WTP. ${ }^{2}$ Voluntariness reflects the degree of freedom people have to avoid exposure to a particular risk (e.g. dying from bungee jumping or in a traffic accident). The fourth determinant is the degree of control people have when exposed to a particular risk. For example, being the driver versus a passenger in a vehicle may generate a different perception of safety. Similarly, the perceived control over dying in different risk contexts might influence decision-making with respect to safety measures. Since the determinants of risk perception are inherently and uniquely related to each risk context, risk perceptions are likely to differ between contexts. Consequently, WTP values for risk reductions of similar size and the VSL may not be independent of risk context.

$$
\mathrm{WTP}_{i}=f(P, Q)
$$

Equation (2) describes individual WTP as a function of personal $(P)$ and risk characteristics $(Q)$. As noted, the shape and level of the WTP function are determined by the individual's risk perception and preferences for the mortality risk faced. Since the probability of dying $q$ affects the VSL through the denominator in (1) and indirectly through $Q$ in (2), we focus on explaining variations in WTP across contexts in the remainder of this paper.

\subsection{Existing Empirical Evidence}

Exposure to mortality risk caused by air pollution is generally perceived as less voluntary and less controllable than road safety. Based on these differences, Revesz (1999) and Rowlatt et al. (1998) predict a higher WTP for reductions in mortality risk in the case of air pollution than for similar risk reductions in the case of road safety. ${ }^{3}$ Cookson (2000) confirms the importance and negative effect of voluntariness and locus of control on stated WTP based on focus group discussions related to prioritizing and valuing risk reductions in six policy contexts. McDaniels et al. (1992) introduce a new determinant, i.e. personal exposure, and observe an increase in WTP if respondents are personally exposed to a particular mortality risk. Subramanian and Cropper (2000) confirm both the importance of personal exposure and the negative effect of degree of control on WTP for life saving programs, but voluntariness is no longer significant. Similar results are found by Chilton et al. (2002), who show that

2 The measurement unit (reductions in the probability of dying from a particular cause) is comparable within and between contexts.

3 Both studies also expect a higher WTP for reductions in air pollution, because environmental causes of death are often associated with a dread of cancer. 
the extent of personal exposure is a significant determinant of WTP, but not locus of control and voluntariness. Savage (1993) finds a negative relationship between awareness and knowledge of the risks people are exposed to and WTP. The picture that emerges is that the risk perception dimensions voluntariness and locus of control have an ambiguous impact on WTP, but these effects do not preclude the existence of an overall context effect on WTP.

Only four primary valuation studies have developed surveys in which WTP was directly contrasted between mortality risk contexts, resulting in similar ambiguous results. In a contingent valuation study Vassanadumrongdee and Matsuoka (2005) find comparable WTP estimates for mortality risk reductions in distinct subpopulations for air pollution and road safety after controlling for personal exposure. Tsuge et al. (2005) observe similar negligible intra-respondent context effects in a choice experiment and show that the timing of the risk reduction and personal characteristics are the main determinants of stated WTP. On the other hand, Alberini and Scasny (2010) find in an Italian choice experiment that mortality risk reductions in the road safety context are valued less compared to similar risk reductions in fatal diseases associated with air pollution, in particular cancer. Beattie et al. (1998) find an intra-respondent discrepancy between WTP for mortality risk reductions from road safety and domestic fires. To date there does not yet exist a meta-analysis with the explicit aim of identifying contextual effects, despite the large number of VSL surveys in various contexts and limited number of primary studies addressing this issue. Several existing VSL meta-analyses acknowledged the potential presence of context effects and adopted control variables. Elvik (1995) and Miller (2000) observe, on average, a higher WTP for occupational safety than for road safety. Another meta-analysis by Takeuchi (2000) reveals that VSL estimates in the environmental context are significantly lower compared to road safety. The primary focus of these meta-analyses was, however, on variations in VSL across countries and sensitivity to scope effects. The meta-analysis presented here differs in scope and attempts explicitly to identify aggregate context effects such that correction factors of WTP for out of context BT purposes can be estimated. The difference in scope is reflected in the underlying study selection criteria and the study presents the first test of the reliability of out of context BT.

\section{Econometric Model}

\subsection{General Model Structure}

Each primary valuation study included in the meta-analysis is assumed to represent a subpopulation of the overall population exposed to mortality risk. Individual $i$ in study $s$ states his WTP $y_{i j s}$ for a specific reduction in mortality risk $j$. Meta-analysis focuses on a representative agent from each sub-population. Equation (3) describes a hierarchical mixed effects meta-regression model (MRM) as used in Moeltner et al. (2007) in which the natural log transform of average WTP $\hat{\bar{y}}_{j s}$ is modeled conditional upon a set of input vectors $\mathbf{z}_{j s}$ and $\mathbf{x}_{j s} .{ }^{4}$ These input vectors generally include an intercept, average subpopulation characteristics (e.g. age, income and gender), risk reduction characteristics (i.e. baseline risk level, size of the risk reduction and risk context) and a set of methodological characteristics $\mathbf{m}_{j s}$ describing the survey design. Most studies include multiple WTP estimates, varying in the size of the risk reduction or baseline risk. Alternatively, studies vary the elicitation approach

\footnotetext{
4 An implicit assumption here is that each study generates consistent estimates of the underlying WTP value. To clarify the notation, vectors are represented by bold letters, matrices in capital letters and subscripts define the associated dimension(s).
} 
across samples or conduct a survey at multiple locations. The row vector $\mathbf{z}_{j s}$, of which $\mathbf{m}_{j s}$ is a sub-vector, is associated with all fixed parameters $\boldsymbol{\beta}$ in the model, and $\mathbf{x}_{j s}$ is a similar input vector associated with the random parameters $\boldsymbol{\beta}_{r s}$ in the model. These random parameters vary across studies and are introduced to control for unobserved heterogeneity between sub-populations. They are assumed to follow a multivariate normal distribution (mvn) with mean vector $\mathbf{b}$ and variance-covariance matrix $\boldsymbol{\Sigma}$. The error term $\varepsilon_{j s}$ is assumed to be i.i.d. normal. Estimation of multiple specifications is possible, including a variance components model. The exact model specifications are described in Section 5.

$$
\begin{aligned}
& \ln \left(\hat{\bar{y}}_{j s} \mid \mathbf{z}_{j s}, \mathbf{x}_{j s}\right)=\mathbf{z}_{j s} \boldsymbol{\beta}+\mathbf{x}_{j s} \boldsymbol{\beta}_{r s}+\varepsilon_{j s} \\
& \text { with } \varepsilon_{j s} \sim n\left(0, \sigma^{2}\right) \text { and } \boldsymbol{\beta}_{r s} \sim \operatorname{mvn}(\mathbf{b}, \boldsymbol{\Sigma})
\end{aligned}
$$

The distributional assumptions imply that the vector of logged WTP values from study $s$ particular study follows a multivariate normal (mvn) distribution. Equation (4) describes the statistical properties of this vector. $n_{s}$ represents the number of observations obtained from study $s$ and $\mathbf{I}_{n_{s}}$ is the $n_{s}$ by $n_{s}$ identity matrix. As $\mathbf{X}_{\mathbf{s}}$ enters the second moment, the specification captures observation and study-specific heteroskedasticity. Furthermore, Eq. (4) denotes that intra-study observations are correlated with each other via the regressors included in $\mathbf{X}_{\mathbf{s}}$. Unobserved elements constant at the study level are captured by the intercept if, dependent on the model specification, it is specified as a random variable (Moeltner et al. 2007). Therefore, observations are no longer treated as independent.

$$
\begin{aligned}
& \ln \left(\hat{\overline{\mathbf{y}}}_{s} \mid \mathbf{X}_{s}, \mathbf{Z}_{s}\right)=\mathbf{Z}_{s} \boldsymbol{\beta}+\mathbf{X}_{s} \boldsymbol{\beta}_{r s}+\boldsymbol{\varepsilon}_{s} \quad \text { with } \\
& E\left(\ln \left(\hat{\overline{\mathbf{y}}}_{s}\right) \mid \mathbf{X}_{s}, \mathbf{Z}_{s}\right)=\mathbf{Z}_{s} \boldsymbol{\beta}+\mathbf{X}_{s} \mathbf{b} \quad \text { and } \\
& E\left(\ln \left(\hat{\overline{\mathbf{y}}}_{s}\right) \ln \left(\hat{\overline{\mathbf{y}}}_{t}\right)^{\prime}\right)= \begin{cases}\mathbf{X}_{s} \boldsymbol{\Sigma} \mathbf{X}_{s}+\sigma^{2} \mathbf{I}_{n_{s}}, & s=t \\
0, & \text { otherwise }\end{cases}
\end{aligned}
$$

\subsection{Bayesian Framework}

To facilitate the comparison of non-nested models, i.e. varying the included and number of random parameters, a Bayesian estimation framework is chosen. One of the advantages of a Bayesian framework in our context is not having to rely on asymptotic theory under a (relatively) small sample size and resulting straightforward finite sample or "exact" interpretation of inferences (Moeltner and Woodward 2009). Equation (5) describes the likelihood function belonging to the specified model, in which $\mathbf{y}$ represents the vector containing all WTP observations, $\mathbf{S}$ the total number of studies and $\mathbf{X}, \mathbf{Z}$ and $\boldsymbol{\beta}_{\mathbf{r}}$ the sample-level equivalents of the study-specific matrices in Eq. (4).

$$
\begin{aligned}
& p\left(\ln (\mathbf{y}) \mid \mathbf{X}, \mathbf{Z}, \boldsymbol{\beta}_{r}, \boldsymbol{\beta}, \sigma^{2}\right)=\prod_{s=1}^{S} \frac{1}{\left(2 \pi \sigma^{2}\right)^{n_{s} / 2}} \\
& \quad \times \exp \left(-\frac{1}{2 \sigma^{2}}\left(\ln \left(\mathbf{y}_{s}\right)-\mathbf{X}_{s} \boldsymbol{\beta}_{r s}-\mathbf{Z}_{s} \boldsymbol{\beta}\right)^{\prime}\left(\ln \left(\mathbf{y}_{s}\right)-\mathbf{X}_{s} \boldsymbol{\beta}_{r s}-\mathbf{Z}_{s} \boldsymbol{\beta}\right)\right)
\end{aligned}
$$

The prior distributions for our model-parameters $\left[\boldsymbol{\beta}, \boldsymbol{\beta}_{r s}, \mathbf{b}, \sigma^{2}, \boldsymbol{\Sigma}\right]$ are specified in Eq. (6). Both beta vectors are assumed to follow a mvn distribution with respective mean vectors $\mu$ and $\mathbf{b}$, and covariance matrices $\mathbf{V}$ and $\boldsymbol{\Sigma}$. As a Bayesian analogue to the classical random effects model, an additional layer of prior distributions is assigned to the components of the distribution on $\boldsymbol{\beta}_{r s}$. As such, the model in is classified as a hierarchical model and we ensure 
that within each study the augmented elements in $\boldsymbol{\beta}_{r s}$ are constant vary across studies. The mean vector $\mathbf{b}$ follows a mvn distribution with mean vector $\mu_{\mathbf{r}}$ and covariance matrix $\mathbf{V}_{\mathbf{r}}$. We select an inverse Wishart distribution with degrees of freedom $\rho$ and symmetric input-matrix $\mathbf{R}$ for the inverse of the covariance matrix $\boldsymbol{\Sigma}$. The variance term $\sigma^{2}$ is assumed to be drawn from an inverse gamma ( $\mathrm{ig}$ ) distribution with shape parameter $\alpha$ and scale parameter $\gamma$.

$$
\begin{aligned}
p(\boldsymbol{\beta}) & =m v n(\boldsymbol{\mu}, \mathbf{V}) \\
p\left(\boldsymbol{\beta}_{r s} \mid \mathbf{b}, \boldsymbol{\Sigma}\right) & =\operatorname{mvn}(\mathbf{b}, \boldsymbol{\Sigma}) \\
p(\mathbf{b}) & =\operatorname{mvn}\left(\boldsymbol{\mu}_{r}, \mathbf{V}_{r}\right) \\
p(\boldsymbol{\Sigma}) & =i W((\rho \mathbf{R}), \rho) \\
p\left(\sigma^{2}\right) & =i g(\alpha, \gamma)
\end{aligned}
$$

Combining the priors with the likelihood function results in a joint posterior distribution for the model parameters $p\left(\boldsymbol{\beta}, \mathbf{b}, \boldsymbol{\Sigma}, \sigma^{2} \mid \mathbf{y}, \mathbf{X}_{r}, \mathbf{Z}\right)$ for which the analytical properties are unknown. We therefore augment the model and apply a Gibbs-Sampler (GS) to obtain a set of analyzable conditional posterior distributions for the individual model parameters (see Appendix A). After a sufficient number of repetitions, the draws from the conditional posterior distributions in the GS will converge to the joint posterior distribution (e.g. Gelman et al. 2004). The moments of the corresponding marginal distributions can be obtained from the series of draws for each parameter.

\subsection{Welfare Predictions}

Forecasting the WTP for a particular reduction in mortality risk based on the specified model requires the derivation of the predictive posterior distribution. Preferably, predictions are made independent and unconditional of the methodological variables included in the original MRM. Hence, our main interest is in the (logged) marginal predictive posterior distribution of WTP $p\left(\ln (\tilde{\mathbf{y}}) \mid \mathbf{f}_{p}, \mathbf{x}_{p}\right)$ where $\mathbf{f}_{p}$ is the sub-vector of $\mathbf{z}_{p}$ not containing the methodological variables in the predictive scenario. The MRM, however, also requires the methodological setting as an input for predictions. Selecting a specific methodological setting affects the generality of the posterior WTP distribution. Moeltner et al. (2007) show that a Bayesian approach offers a convenient way to overcome this problem compared to classical BT practices. It requires the identification of the set of permissible methodological combinations $\mathbf{T}$ and the assignment of a probability $\pi_{t}$ of occurring to each element $\mathbf{m}_{t}$ in $\mathbf{T}$. These probabilities can be based on for instance observed sample shares or a uniform probability. Since $\pi_{t}$ is arbitrarily assigned, it can be modeled independent of all other model components. Within the forecasting procedure we use these $\pi_{t}$ 's as weights to average the effects of the methodological characteristics out of the predictive distribution (see Eq. 7) ${ }^{5}$ In Eq. 7 the original MRM-parameters $\left[\boldsymbol{\beta}, \mathbf{b}, \boldsymbol{\Sigma}, \sigma^{2}\right]$ are combined in $\boldsymbol{\theta}$. The procedure to simulate the predictive density of WTP unconditional on the methodological characteristics is described in more detail in Moeltner et al. (2007).

$$
p\left(\ln (\tilde{\mathbf{y}}) \mid \mathbf{f}_{p}, \mathbf{x}_{p}\right)=\int_{\theta}\left(\sum_{t=1}^{T} p\left(\ln (\tilde{\mathbf{y}}) \mid \boldsymbol{\theta}, \mathbf{f}_{p}, \mathbf{x}_{p}, \mathbf{m}_{t}\right) \pi_{t}\right) p(\boldsymbol{\theta} \mid \mathbf{y}, \mathbf{X}, \mathbf{Z}) d \boldsymbol{\theta}
$$

\footnotetext{
${ }^{5}$ Note that, for each methodological setting $\mathbf{m}_{t}$ in $\mathbf{T}$ we are able to derive the predictive distribution.
} 


\section{Data Description}

\subsection{Selection Criteria}

As recommended by Allen et al. (2006), we restrict the meta-analysis to VSL studies using stated preference (SP) methods. The explicit formulation of WTP questions in SP studies allows capturing the effect of risk context and also reduces possible embedding effects by focusing only on the valuation of mortality risks and not on related morbidity effects (Schwab Christe and Soguel 1995). ${ }^{6}$ Moreover, we only include studies using the contingent valuation (CV) method. Program choice studies, like choice experiments, are not considered for several reasons. First, program choice studies directly estimate the VSL as a marginal rate of substitution, whereas CV studies elicit WTP for a specific risk reduction, our dependent variable, and approximate the VSL accordingly (see Eq. 1). ${ }^{7}$ Second and closely related, by presenting multiple attribute levels and choice cards the actual policy being implemented remains unspecified and unclear to both the respondent and the researcher (Collins and Vossler 2009). Apart from potential incentive compatibility issues (Carson and Groves 2007) it also remains unclear which explanatory variables should be included in the MRM for a specific CE study. Similar problems related to the inclusion of CE estimates in meta-models have been noted by Johnston et al. (2006) in the context of valuing changes in recreational fish catch. Third, by including multiple risk contexts into a single experiment (e.g. Tsuge et al. 2005; Alberini and Scasny 2010) the respondent may suffer from misconceptions of the baseline risk and interpret risk reductions of similar size different across contexts (Beattie et al. 2000). As recommended by Smith and Pattanayak (2002), a single Hicksian welfare measure, i.e. the compensating surplus, is taken as the response variable in the MRM. ${ }^{8}$

The first selection criterion screened primary valuation studies for a specified cause of death to identify the risk context. Relevant context specific CV studies were identified based on a keyword search in several search engines and by screening the studies included in previous meta-analyses. Our screening process covered both published papers as well as the grey literature in order to reduce the possibility of publication bias (e.g. Rothstein et al. 2005; Rosenberger and Stanly 2006). Two main categories were identified within the environmental context. The first category concerned mortality risk reductions from air pollution. The second category uses a common survey design developed by Krupnick et al. (1999), but does not specify a specific cause of death. The purpose of these studies was to develop a VSL measure generally applicable in environmental contexts. The search and selection process identified 26 studies, both published and unpublished. In total 77 VSL estimates are included in the database. Five address air pollution, 52 road safety and 20 estimates 'context free'. A detailed description of the search and selection process is provided in Appendix B.

\footnotetext{
6 Mortality risk is an elusive concept to individuals and the extent to which the researchers succeed in communicating the small risk reductions to the respondents is essential for the validity of the WTP measure. Some elicitation approaches are more successful than others in deriving a valid value measure (Carson et al. 2001; Miller and Guria 1991).

7 Within CE studies, the attributes are generally included in the utility function in a linear form (e,g. Tsuge et al. (2005) and Alberini and Scasny (2010). This implies that limited sensitivity to scope effects are not controlled for, while they are frequently observed in CV studies (Hammitt and Graham 1999). Transforming the VSL point estimate, i.e. the negative ratio of the risk reduction and cost coefficient is therefore likely to be inaccurate.

8 It should be noted that SP VSL estimates are generally found to be higher compared to revealed preference estimates (de Blaeij et al. 2003). Strand (2001) furthermore argues that SP studies result in more stable VSL estimates.
} 


\subsection{The Dependent Variable}

Considerable variation in VSL estimates, both within and between risk contexts, is reported in Table 1. The VSL ranges within respectively the air pollution, road safety and general context between 0.13 and 5.43 million, 0.73 and 33.58 million, and 0.55 and 8.91 million dollar (in 2004 PPP converted prices). At first sight and contrary to expectations, the VSL in the road safety context appears to be relatively higher compared to the two other risk contexts. However, as noted in Section 2, we focus here on variations in WTP across risk contexts instead of the VSL, because in Eq.(1) and Eq. (2) (i) risk perception primarily affects WTP and (ii) the size of the risk reduction $q$ influences the VSL along both the nominator and denominator (Hammitt and Graham 1999).

\subsection{The Control Variables}

\section{Risk Characteristics}

From a theoretical perspective, the WTP function can be assumed to be linear for small changes in mortality risk (Hammitt and Graham 1999). The VSL estimates can therefore be stipulated to be constant due to a proportional increase in WTP compared to the size of the risk reduction. Most of the studies in the database, however, observed less than proportional increases in WTP. Hence, a control variable for the size of the risk reduction (DELTA) is included. WTP for mortality risk reductions is likely to increase with higher baseline risks due to a 'dead anyway' effect (Pratt and Zeckhauser 1996). ${ }^{9}$ At low risk levels individuals may tend to neglect their risk exposure, thereby reducing marginal WTP (Sunstein 2004). Empirical evidence regarding the effect of baseline risk on WTP is limited and mixed (Covey 2002). Both the size of the risk reduction and the baseline risk level (BASELINE) are described in this meta-analysis by the number of (prevented) annual deaths per 100,000 people. In addition, we define two dummy variables for respectively air pollution (AIR) and road safety (ROAD) and use general mortality risk as the reference context.

\section{Respondent Characteristics}

The theoretical and empirical relationship between age and the VSL is ambiguous (DeShazo and Cameron 2005; Dockins et al. 2004; Evans and Smith 2006; Krupnick 2007; Sunstein 2004). Older people have a lower life expectancy. Therefore, a "senior death discount" may exist resulting in a lower VSL. However, these remaining years may be more valuable to older people than younger people. Income is expected to have a positive effect on WTP due to a relaxation of the budget constraint. In addition, in the road safety context, men are found to underestimate the risk they face compared to women (Andersson 2007). To capture these potential effects, we attempted to include control variables for age, income and gender. ${ }^{10}$ Many studies, however, failed to report relevant demographic respondent characteristics, such that external data sources had to be consulted (World Development Indicators). Insufficient information was available, also from these external sources, to include respondent

\footnotetext{
9 In an expected utility setting, the extra money spent has a larger probability of being drawn from the non-survival state.

10 Health status could not be included in the empirical analysis presented here, due to the limited and incompatible reporting of respondents' health status in our database. Alberini et al. (2004) find no support for the hypothesis that ill people are willing to pay less for mortality risks reductions compared to healthy people.
} 


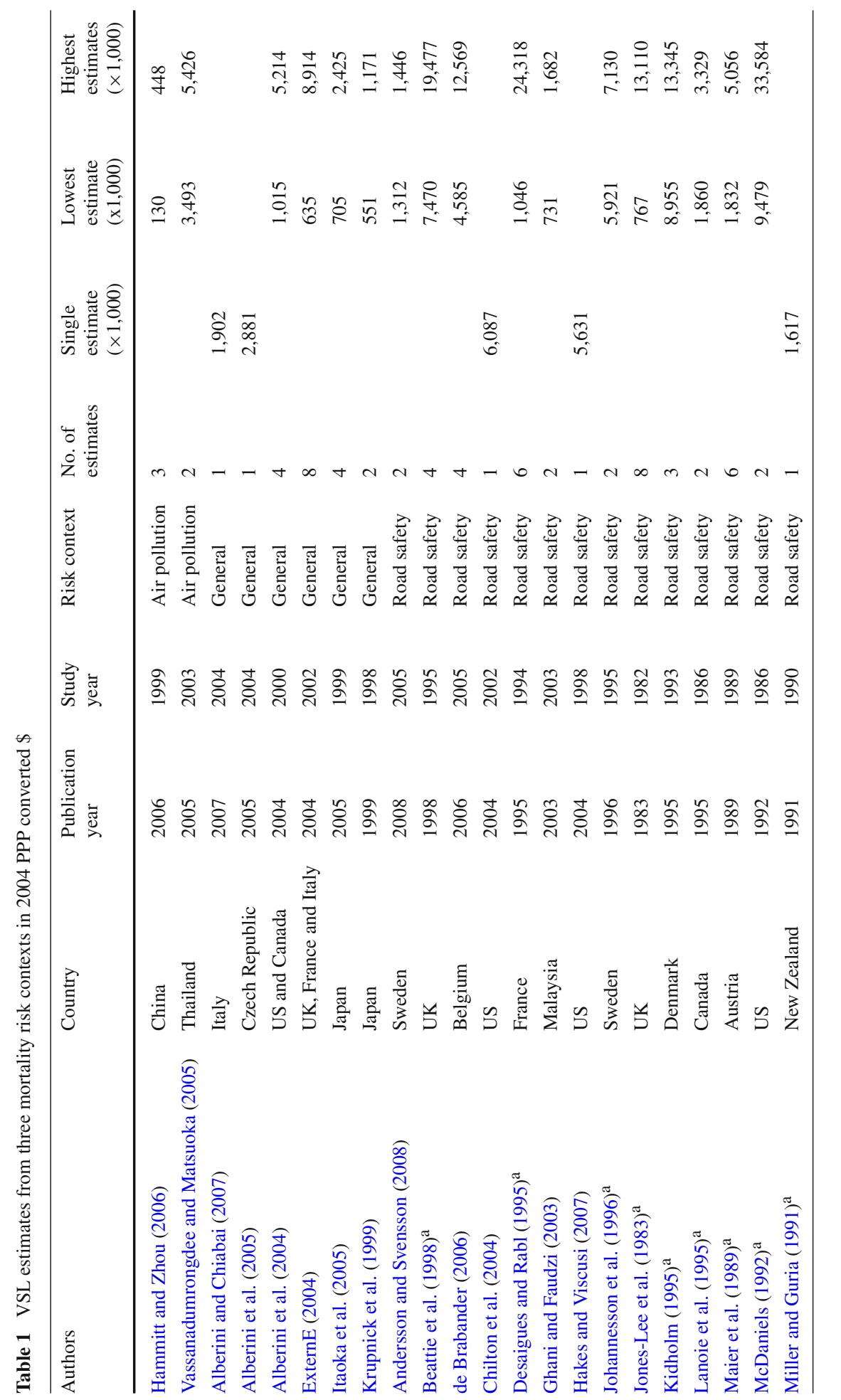




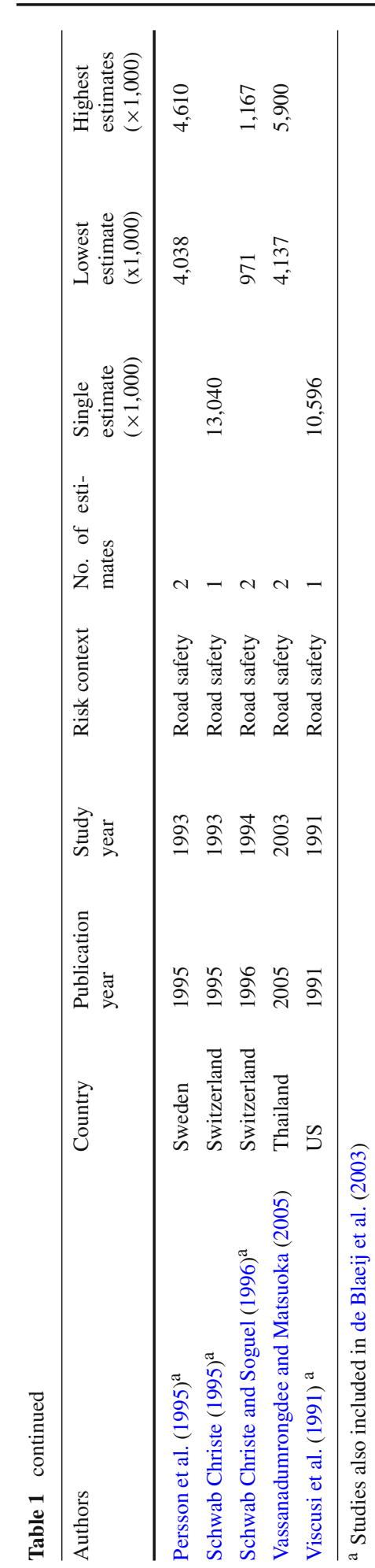


age. ${ }^{11}$ A set of indicator variables is included to control for possible differences between the continents in which the studies were conducted: Asia, Eastern Europe, Western Europe, New Zealand and North-America. Western Europe is used as the baseline category in the analysis.

\section{Methodological Characteristics}

Several question formats are used in the CV literature to elicit WTP for mortality risk reductions, primarily open-ended (OE), payment cards (PC) and dichotomous choice (DC) questions. A common finding is that the DC referendum format has a positive effect on WTP (e.g. Bateman et al. 1995). We use dummy variables for PC and DC to describe the elicitation method and the OE format is treated as the baseline category. The way mortality risk is presented and described in the survey is expected to affect risk perception and the interpretation of the good to be valued. To control for the effect of risk communication, we include a dummy variable LIVES, which has the value one for estimates based on a number of saved lives formulation and zero if formulated in terms of probabilities. Graphical devices are often used to communicate the change in risk to respondents. Commonly used formats are 'risk ladders' and cards displaying 'dots' (Corso et al. 2001). Both devices are accounted for in the meta-analysis presented here through the dummy variables LADDER and DOTS, using no visual aid as the reference category. Another dummy variable is included to capture the effect of formulating the valuation question in terms of willingness to accept compensation (WTAC) instead of WTP. WTAC for risk increases is expected to be higher than WTP for a similar risk reduction, because people do not have to consider their budget constraint and the potential presence of an endowment effect under WTAC (e.g. Guria et al. 2005). Since WTAC questions are concerned with increases in risk, absolute changes in risk levels are used in the analysis.

Finally, two dummy variables control for risk reductions presented as a public good (PUBLIC) and if the risk reductions involves the protection of additional household members or passengers (HH_EXP). Private goods serve as the baseline category and only affect the respondent. A higher WTP is expected for private goods also protecting others. Risk reductions offered by public goods are not directly related to the individual's risk exposure and offer opportunity for free riding effects, such that a lower WTP is expected for public goods.

\section{Meta-Analysis Results}

In this section the 77 WTP estimates are analyzed to examine whether a systematic variation exists in WTP across mortality risk contexts whilst controlling for a wide variety of other influencing factors as outlined above. Four alternative specifications of the MRM were estimated, varying in the way unobserved heterogeneity is modeled. The first MRM does not control for unobserved heterogeneity at the study level and only includes fixed coefficients, while the second and third MRM introduce a single random coefficient for respectively the intercept and DELTA. The fourth MRM comprises random coefficients for both variables. The random coefficients capture unobserved elements at the study level and allow for differences in sensitivity to scope across studies.

${ }^{11}$ Note that none of the existing meta-analyses controls for these demographic respondent characteristics for the same reason. 
Table 2 Descriptive statistics for 77 WTP observations

\begin{tabular}{|c|c|c|c|c|c|c|}
\hline Variable name & Description & Mean & $\mathrm{SD}$ & Min & $\operatorname{Max}$ & $N$ \\
\hline WTP & Mean WTP (2004 PPP \$) & 371.89 & 345.12 & 23 & 1,849 & 77 \\
\hline \multicolumn{7}{|c|}{ Risk characteristics } \\
\hline BASELINE & $\begin{array}{l}\text { Risk level before the change, denoted in } y \\
\text { people dying per } 100,000\end{array}$ & 301 & 527 & 5 & 1,989 & 77 \\
\hline DELTA & $\begin{array}{l}\text { Absolute change in the risk level denoted in } \\
x \text { people saved per } 100,000\end{array}$ & 16 & 23 & 0.09 & 100 & 77 \\
\hline AIR & $\begin{array}{l}\text { Dummy variable, value }=1 \text { if the study } \\
\text { concerns the air pollution context, } 0 \\
\text { otherwise }\end{array}$ & 0.065 & 0.246 & 0 & 1 & 77 \\
\hline GENERAL & $\begin{array}{l}\text { Dummy variable, value }=1 \text { if the study } \\
\text { concerns the general mortality risk context } \\
\text { (i.e. Krupnick et al. studies), } 0 \text { otherwise }\end{array}$ & 0.234 & 0.438 & 0 & 1 & 77 \\
\hline ROAD & $\begin{array}{l}\text { Dummy variable, value }=1 \text { if the study } \\
\text { concerns the road safety context, } 0 \\
\text { otherwise }\end{array}$ & 0.675 & 0.471 & 0 & 1 & 77 \\
\hline \multicolumn{7}{|c|}{ Respondent characteristics } \\
\hline GENDER & $\begin{array}{l}\text { Percentage of females in the survey or } \\
\text { population }\end{array}$ & 49.59 & 8.21 & 20 & 69 & 77 \\
\hline INCOME & $\begin{array}{l}\text { Average household income of the } \\
\text { respondents (2004 PPP\$) }\end{array}$ & 33,749 & 11,684 & 3,975 & 58,473 & 77 \\
\hline ASIA & $\begin{array}{l}\text { Dummy variable, value }=1 \text { if study was } \\
\text { carried out in Asia, } 0 \text { otherwise }\end{array}$ & 0.195 & 0.399 & 0 & 1 & 77 \\
\hline $\mathrm{EE}$ & $\begin{array}{l}\text { Dummy variable, value }=1 \text { if study was } \\
\text { carried out in Eastern Europe, } 0 \text { otherwise }\end{array}$ & 0.013 & 0.114 & 0 & 1 & 77 \\
\hline NA & $\begin{array}{l}\text { Dummy variable, value }=1 \text { if study was } \\
\text { carried out in North America, } 0 \text { otherwise }\end{array}$ & 0.143 & 0.352 & 0 & 1 & 77 \\
\hline $\mathrm{NZ}$ & $\begin{array}{l}\text { Dummy variable, value }=1 \text { if study was } \\
\text { carried out in New Zealand, } 0 \text { otherwise }\end{array}$ & 0.013 & 0.114 & 0 & 1 & 77 \\
\hline \multicolumn{7}{|c|}{ Methodological characteristics } \\
\hline WTAC & $\begin{array}{l}\text { Dummy variable, value }=1 \text { if WTAC } \\
\text { questions were asked, } 0 \text { for WTP questions }\end{array}$ & 0.078 & 0.270 & 0 & 1 & 77 \\
\hline PUBLIC & $\begin{array}{l}\text { Dummy variable, value }=1 \text { if risk reduction } \\
\text { is in the form of a public good, } 0 \text { otherwise }\end{array}$ & 0.208 & 0.408 & 0 & 1 & 77 \\
\hline HH_EXP & $\begin{array}{l}\text { Dummy variable, value }=1 \text { if the good } \\
\text { affecting the whole household or all } \\
\text { passengers, } 0 \text { otherwise }\end{array}$ & 0.039 & 0.195 & 0 & 1 & 77 \\
\hline LIVES & $\begin{array}{l}\text { Dummy variable, value }=1 \text { if WTP } \\
\text { questions were formulated in \# of lives } \\
\text { saved, } 0 \text { for probabilities }\end{array}$ & 0.117 & 0.323 & 0 & 1 & 77 \\
\hline LADDER & $\begin{array}{l}\text { Dummy variable. Value }=1 \text { for using risk } \\
\text { ladders to communicate risk levels, } 0 \\
\text { otherwise }\end{array}$ & 0.078 & 0.270 & 0 & 1 & 77 \\
\hline DOTS & $\begin{array}{l}\text { Dummy variable. Value }=1 \text { for using square } \\
\text { grids filled with dots to communicate risk } \\
\text { levels, } 0 \text { otherwise }\end{array}$ & 0.403 & 0.494 & 0 & 1 & 77 \\
\hline $\mathrm{PC}$ & $\begin{array}{c}\text { Dummy variable, value }=1 \text { if a payment } \\
\text { card is used to elicit WTP, } 0 \text { otherwise }\end{array}$ & 0.130 & 0.338 & 0 & 1 & 77 \\
\hline $\mathrm{DC}$ & $\begin{array}{l}\text { Dummy variable, value }=1 \text { if a dichotomous } \\
\text { choice format is used to elicit WTP, } 0 \\
\text { otherwise }\end{array}$ & 0.403 & 0.494 & 0 & 1 & 77 \\
\hline
\end{tabular}

The descriptive statistics for the dependent and control variables are provided in Table 2. Most observations (68\%) are in the road safety context and extensive variation in applied risk levels is observed. The mean values for the methodological dummy variables are illustrative 
for the wide variety in study designs. Due to the use of external data sources limited variability is observed for gender ( $\%$ of females) and income both within and between studies. The mean and standard deviation of the intercept are highly affected by the in- or exclusion of gender and income in our model specifications. Furthermore, the Gibbs Sampler for MRMs 2 and 4 becomes highly inefficient and shows convergence problems by including gender and income. This indicates that there is not enough information in the data to identify the effect of these respondent characteristics on WTP. We therefore only present the results of the estimations not controlling for gender and income. ${ }^{12}$

The first two columns for each MRM in Table 3 display the estimated mean and standard deviation of the posterior distribution for each model parameter. The third column reports numerical standard errors (NSE's) for the posterior means adjusted for autocorrelation (Geweke 1992). The prior values in the analysis are set to $\boldsymbol{\mu}=0, \mathbf{V}=10^{*} \mathbf{I}_{k f}, \boldsymbol{\mu}_{\mathbf{r}}=0$, $\mathbf{V}_{\mathbf{r}}=10^{*} \mathbf{I}_{k r}, \alpha=\gamma=1 / 2, \rho=k_{r}$ and $\mathbf{R}=\left(1 / k_{r}\right)^{*} I_{k r}$, where $k_{f}$ and $k_{r}$ refer to the number of fixed and random coefficients. Hence, a set of relatively non-informative priors is specified. For both BASELINE and DELTA we set the prior distribution at mean of 0.5 and variance 0.25 , since the use of their natural logs transforms their coefficients into elasticities. The empirically observed limited sensitivity to scope effects (Hammitt and Graham 1999) imply that their mean values can be set between 0 and 1 . Standard deviations are high enough to remain relatively uninformative. The starting values for $\mathbf{b}$ and $\sigma^{2}$ in the GS are taken from standard OLS estimation results of the specified model. For $\boldsymbol{\Sigma}$ we use the identity matrix as a starting value. Every run of the GS consists of 50,000 burn-in replications and 10,000 maintained draws. To assess convergence of the GS Geweke (1992), convergence diagnostic is applied.

In all four MRMs the posterior means for AIR and GENERAL are positive, indicating a WTP premium for mortality risk reductions in the air pollution and general mortality risk contexts compared to road safety. These mean effects exhibit lower posterior standard deviations when controlling for unobserved heterogeneity in MRMs 2, 3 and 4. The support of the posterior density for GENERAL is highly sensitive to the model specification, while the support for AIR is relatively stable across specifications. Similar observations were made in the estimations including gender and income. Evaluated at a mean of about 0.60 , our results imply that WTP (and VSL) estimates from the road safety context should be multiplied by a factor 1.8 to be applicable in the air pollution context. This correction factor is close to the proposal by Rowlatt et al. (1998). Savage Dickey Density Ratios provide no support for the conjecture that the distributions on AIR and GENERAL are equivalent. Consequently, transferring WTP estimates based on the Krupnick et al. design to either the road safety or air pollution context is likely to result in overestimation of the policy benefits. Since we are working with posterior densities, these mean effects are surrounded by a degree of uncertainty. Nevertheless, the major share of the support for the posterior densities of the context dummies is located in the positive domain. Hence, our results indicate the presence of a context effect, whilst controlling for other influential factors. ${ }^{13}$ Policy makers should therefore control for risk context in an 'out of context' BT exercise.

Besides this main result, we briefly discuss our findings with respect to the other control variables. As expected, the coefficients for DELTA are smaller than unity across all models, implying that sensitivity to scope is less than proportional. Baseline risk levels appear to have

\footnotetext{
12 In all models the natural log transformations of WTP, BASELINE, DELTA and income are used, as they provide a better model fit. Results including gender and income are available upon request from the authors. 13 In the classical analogue of MRM 1 the context effects are also significant, but remarkably higher. Given the small sample size, classical statistical approaches, as applied in the existing literature, may overestimate the correction factors.
} 


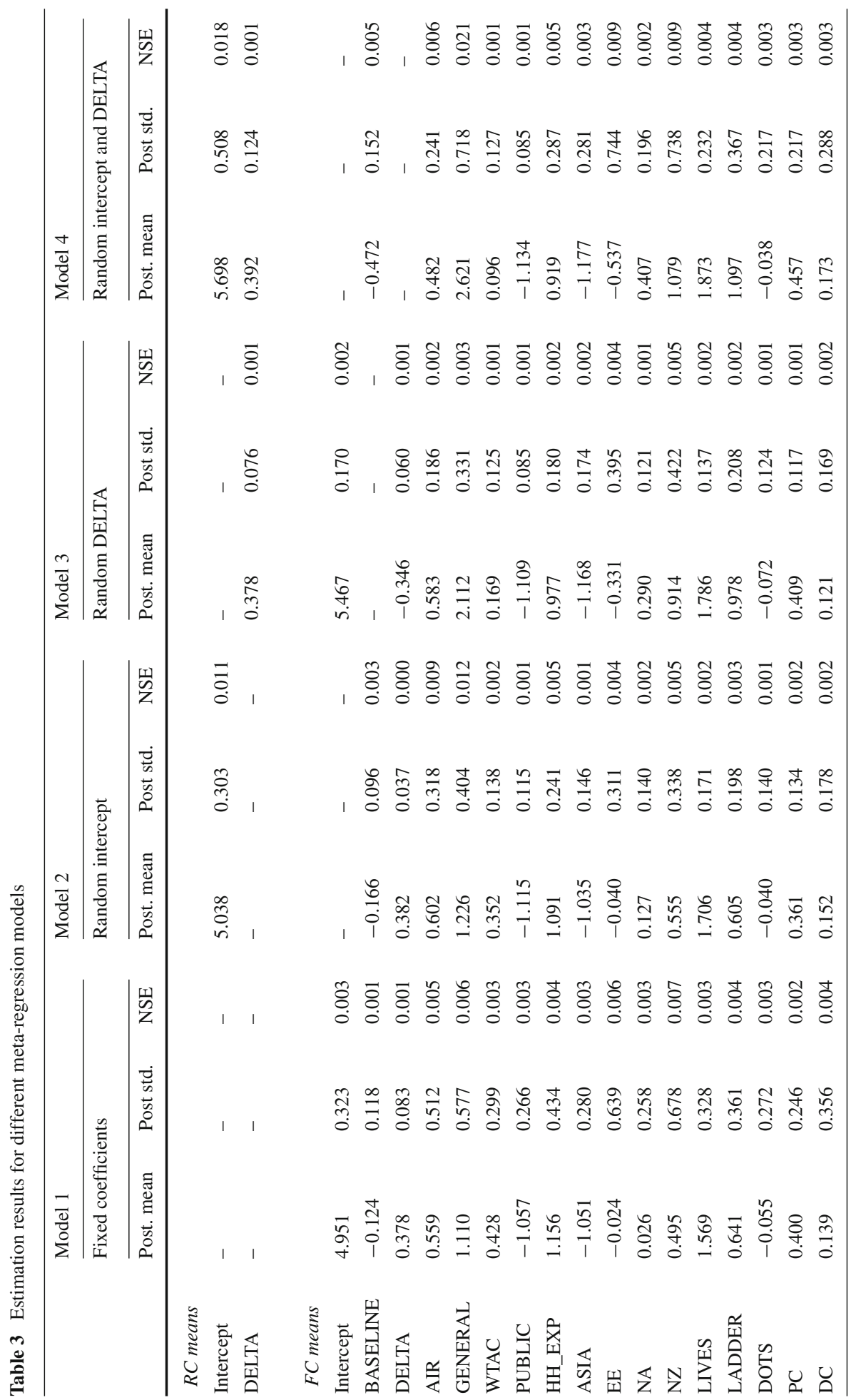




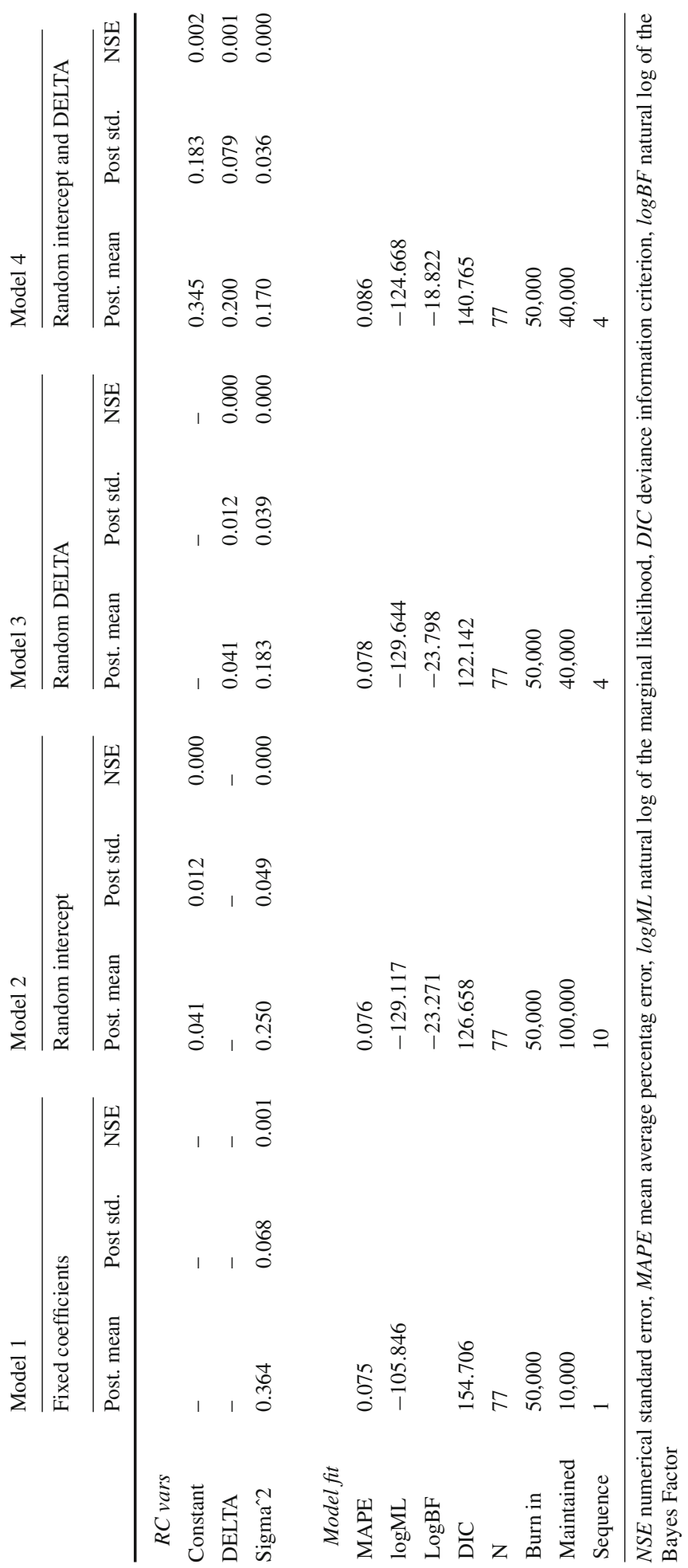


a negative effect on WTP, though the posterior standard deviation is high in MRMs 1 and $2 .{ }^{14}$ With respect to the methodological characteristics, most posterior means have the expected sign. WTP rises if more people within the household benefit from the private risk reduction. People are willing to pay less for mortality risk reductions presented as public goods. WTP increases by formulating the valuation question in terms of the number of lives saved or by using risk ladders to communicate a change in risk level. Asian studies report substantially lower WTP values, also after controlling for income. Compared to the open-ended elicitation format, WTP tends to be higher when payment cards are used. Posterior standard deviations for WTAC, Eastern Europe, North America, New Zealand, DOTS and DC are relatively high in certain models, such that their effect on WTP can be labeled as ambiguous.

Concerning the model specification, in MRMs 2 and 3 there is a clear (non-zero) heterogeneity effect, which is highlighted by the low posterior standard deviations of the variances of the random coefficients. The effect is not very pronounced in MRM 2 since the variance of the random intercept is small compared to its posterior mean. According to MRM 3 respondents vary in sensitivity to scope across studies. Although the posterior standard deviations on the variances of the random coefficients rise somewhat, the heterogeneity effects are more pronounced in MRM 4.

For model comparison, a set of classical and Bayesian goodness-of-fit measures is listed in Table 3. Details about their calculation and interpretation can be found in Moeltner et al. (2007). With respect to the mean absolute percentage error (MAPE), MRM 1 performs best, closely followed by MRMs 2 and 3. The marginal likelihood (ML) can be loosely interpreted as the probability of observing the data given that the specified model is correct (Chib 1995). Bayes Factors (BFs) compute the ratio of the ML between two models. In Table 3 the logged versions of the ML's and BF's are presented and compared to MRM 1. In terms of the BF scale reported in Kass and Raftery (1995), the superior fit of MRM 1 would be labeled as 'decisive'. In part this is a result of its relative parsimony in parameters and associated diffuse priors compared to the other models. MRMs 2 and 3 have almost similar MLs with a slightly better fit for MRM 2. Even though MRM 4 includes more parameters than MRMs 2 and 3, BFs comparing MRM 4 to MRM 2 and 3 indicate positive support for MRM 4 on the Kass and Raftery (1995) scale. The Deviance Information Criterion (DIC) is commonly used to compare Bayesian models on their ability to predict out of sample values. In our case MRM 3 has the best (lowest) DIC while MRM 1 performs worst. However, since the model fit of MRM 1 is 'decisively' better than all other models, any further analysis and discussion in this paper will be based on this model.

\section{Benefits Transfers}

In this section we conduct a purely predictive functional BT exercise with the single purpose of illustrating the degree of potential over- or underestimation of WTP by incorrectly specifying the target risk context. Using the method described in Section 3.3 we generate a set of context specific predictive posterior distributions (PPDs) based on a common policy setting, i.e. keeping DELTA, BASELINE and the geographical location constant, but varying the context indicator across scenarios. If context would not have an effect on WTP we would expect broad overlap of these PPDs. This exercise is more informative than our evaluation at the mean effects as conducted in Section 5, because the PPDs reflect all the underlying param-

\footnotetext{
14 Applied baseline risk levels are highest in the general mortality risk context, followed by air pollution and road safety. Most likely the increase in the posterior mean for GENERAL from MRM 1 to 4 is compensated by the coefficient for baseline risk. The results confirm this, but the context effect remains.
} 
Table 4 Welfare predictions across contexts Scenario: DELTA $=10$ and BASELINE $=100$

\begin{tabular}{llllll}
\hline & Mean & SD & NSE & Pct 2.5 & Pct 97.5 \\
\hline $\begin{array}{llll}\text { Ln(WTP) } \\
\text { Road }\end{array}$ & 5.429 & & & & 6.154 \\
Air & 5.987 & 0.365 & 0.003 & 4.722 & 6.831 \\
General & 6.539 & 0.436 & 0.004 & 5.124 & 7.336 \\
WTP & & 0.411 & 0.003 & 5.717 & 470.70 \\
Road & 243.68 & & & & 925.88 \\
Air & 437.75 & 93.25 & 0.66 & 112.35 & $1,534.16$ \\
General & 752.05 & 199.12 & 1.70 & 168.08 & 303.90 \\
VSL & & 321.11 & 2.27 & & $4,706,951$ \\
Road & $2,436,785$ & 932,486 & 6,638 & $1,123,524$ & $9,258,778$ \\
Air & $4,377,508$ & $1,991,229$ & 16,951 & $1,680,775$ & $15,341,577$ \\
General & $7,520,514$ & $3,211,124$ & 22,689 & $3,039,005$ & \\
\hline
\end{tabular}

eter uncertainty, including context effects. Furthermore, the predictions are unconditional on any methodological characteristic. This clearly illustrates the advantage of using a Bayesian approach. Our example focuses on a mortality risk reduction policy in Western Europe; as such the geographical location is assumed to be under control of the policy agency and is not treated as a methodological variable. A set of 108 permissible methodological combinations is identified. The observed frequencies in the sample are used to assign a probability $\pi_{t}$ to each specific methodological combination.

Table 4 presents the predictions for a single policy setting to communicate our main observations. In this setting the size of the risk reduction and the baseline risk level are set to respectively 10 and 100 in 100,000. The differences in mean log WTP confirm the obtained results in Table 3 regarding the context dummies. Policy makers are likely to underestimate WTP if road safety values are used to generate predictions in the air pollution and general mortality risk context. In particular, the relatively small standard deviations of comparable size highlight that the support of the predictive distributions varies across contexts. ${ }^{15}$ The latter is also confirmed by the $95 \%$ confidence interval presented in the last two columns of Table 4 . Though the studies in the general mortality risk context were originally designed for applications in the environmental context, there is a risk of overestimating WTP in the air pollution context using the Krupnick et al. (1999) design. ${ }^{16}$ The results are illustrative for similar scenarios we ran using alternative settings for DELTA and BASELINE. They highlight that due to the limited overlap in the support of the context specific distributions 'out of context' BT errors may arise.

Naturally, the interest of the policy maker will be in the distributions of WTP and the VSL. The exponential transformation increases the variance and right-skews the predictive distribution, but does not affect our main conclusions. In the presented case, mean VSL in the road safety context is 2.43 million dollar, which is respectively 50 and $31 \%$ of the mean VSL

\footnotetext{
15 The estimated standard deviations across scenarios all range between 0.37 and 0.44 , resulting in relatively narrow distributions of mean log WTP.

16 Most likely, a substantial part of this overestimation is caused by multi-collinearity of the context variable with other control variables like BASELINE, DOTS and DC. Applied baseline risk levels in the general mortality context risk are usually higher compared to the other contexts and the surveys follow a common survey design.
} 


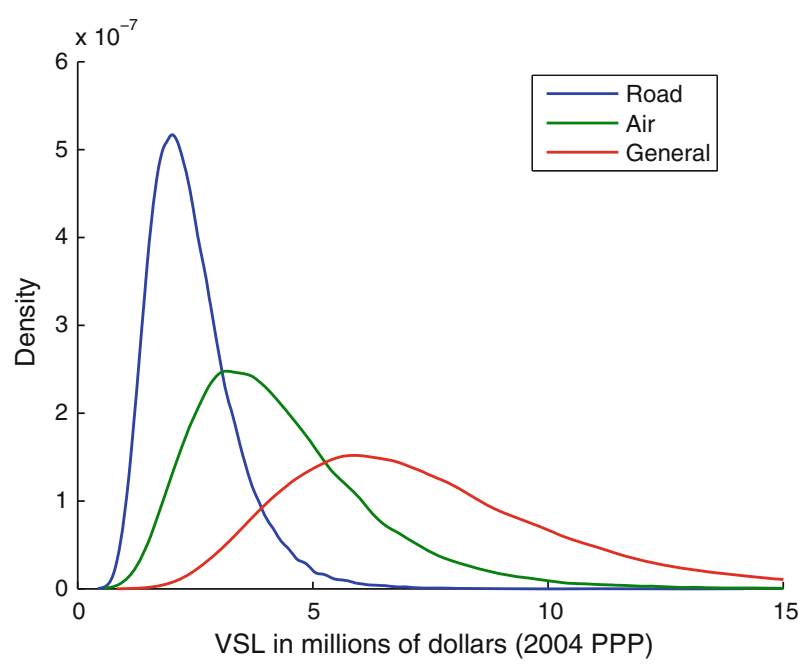

Fig. 1 Context specific predictive VSL distributions

in the air pollution and general mortality risk context. The values covered by the confidence intervals are comparable to other empirical studies, but only serve illustrative purposes here. Figure 1 illustrates there is limited overlap in the PPDs for the VSL across contexts and therefore should warn policy makers that ignoring contextual effects in VSL BT exercises comes at a price of higher transfer errors.

\section{Conclusions}

The contributions of this paper are twofold. First, it clearly illustrates that 'out of context' benefits transfers of VSL values should be conducted carefully. Estimation results highlight that the variation in VSL values across studies can be explained by controlling for risk context in combination with other risk and study specific characteristics. Substantial risks of over- and underestimation arise when policy makers do not appropriately control for the risk contexts associated with both the source studies and policy site(s). The limited overlap observed in our context specific predictive VSL distributions in a BT exercise highlights that there exists little support for 'out of context' transfers. This result confirms generally mentioned concerns in literature reviews and empirical studies that the VSL may vary across risk contexts due to differences in risk perceptions and the population at risk. Second, this paper is the first meta-analysis that explicitly estimates a correction factor to transfer VSL values from the road safety context to air pollution policies. Evaluated at the mean, values from the road safety context should be multiplied by a factor 1.8 in order to be applicable in the air pollution context. This value is close to the previously proposed correction factor 2.0 by Rowlatt et al. (1998). Given the low number of studies in the air pollution context, it is not surprising that the correction factor is associated with a substantial degree of uncertainty. Naturally, this provides a call for more research to improve the efficiency of this estimate. We do, however, believe that our results provide a credible message to policy makers. Predicted VSL estimates are within the range of empirically observed VSL values. Our strict study selection criteria allowed us to directly contrast WTP values for mortality risk reductions in 
different context. Besides our focused dataset, the Bayesian model is suitable to take into account non-nested hierarchical relationships and account for the limited number of WTP observations in the dataset without relying on asymptotic theory. The posterior predictive distributions generated by means of our Bayesian model offer two additional insights. First, they reflect all uncertainty about the predicted VSL, including uncertainty caused by imprecise parameter estimates. As such the limited overlap in the domain of the context specific predictive distributions clearly show that 'out of context' BT should be treated with care. Second, the effect of methodological characteristics is filtered out of these predictive distributions. Hence, the policy maker no longer needs to define a specific elicitation setting in order to generate a BT value.

Despite the fact that the main conclusions of this paper provide a clear policy message, some caveats remain to be discussed. We find a WTP premium for studies in the general mortality risk context over the air and road safety context, while this group of studies was designed for applications in the environmental context. The high associated correction factor might be of concern, but should not be taken at face value. The studies within the general mortality risk context are based on the same study design. Consequently, specific methodological and risk characteristics are likely to be highly correlated with the indicator variable for the specific context. This in combination with the limited number of observations in our database is likely to result in multi-collinearity between parameter estimates. We therefore did not explicitly discuss the correction factor associated with this risk context. The main message of this paper, however, still holds. Overall, 'out of context' benefits transfer exercises are likely to be associated with over- or underestimation of WTP and the VSL.

The limited availability of VSL estimates in specific risk contexts forces policy makers to engage in either risky BT exercises or conduct a costly new original valuation study. Correction factors are needed to reduce the size of 'out of context' transfer errors in BT exercises. Additional research is, however, required to reduce the uncertainty surrounding the correction factors and VSL values in general. In particular at the level of the individual, it is required to better identify the relationships between personal characteristics, survey design, context effects, risk perceptions and VSL. Alternative segments of the population are affected differently by mortality risks. Therefore they are likely to vary in their risk perceptions and risk preferences. Unfortunately, limited information from source studies prevented us to include these relationships adequately in our meta-analysis. WTP for mortality risk reductions is not invariant of the elicitation method, including risk communication. All these factors, in combination with the specific risk context, affect an individual's risk perception and should therefore be controlled for in future analyses.

Acknowledgments We would like to thank Arianne de Blaeij for sharing her VSL road safety database and Vanessa Daniel for useful comments on an earlier draft. We would also like to thank an anonymous reviewer for providing helpful suggestions to improve the paper. This report was carried out under the Dutch National Research Programme "Climate Changes Spatial Planning” (www.klimaatvoorruimte.nl).

Open Access This article is distributed under the terms of the Creative Commons Attribution Noncommercial License which permits any noncommercial use, distribution, and reproduction in any medium, provided the original author(s) and source are credited. 


\section{Appendix A-Conditional Posterior Distributions}

Presented here are the conditional posterior distributions for the hierarchical model specified in Section 3, from which the Gibbs Sampler takes draws $(R 1)$ for the individual model parameters.

$$
\begin{aligned}
& p\left(\boldsymbol{\beta}_{R 1} \mid \mathbf{b}_{R 1}, \boldsymbol{\Sigma}_{R 1}, \sigma_{R 1}^{2}, \mathbf{y}, \mathbf{X}, \mathbf{Z}\right)=\operatorname{mvn}\left(\boldsymbol{\mu}_{R 1}, \mathbf{V}_{R 1}\right) \text { where } \\
& \mathbf{V}_{R 1}=\left(\mathbf{V}^{-1}+\sum_{s=1}^{S} \mathbf{Z}_{s}^{\prime}\left(\mathbf{X}_{s} \boldsymbol{\Sigma}_{R 1} \mathbf{X}_{s}^{\prime}+\sigma_{R 1}^{2} \mathbf{I}_{n_{s}}\right)^{-1} \mathbf{Z}_{s}\right)^{-1} \\
& \boldsymbol{\mu}_{R 1}=\mathbf{V}_{R 1}\left(\mathbf{V}^{-1} \boldsymbol{\mu}+\sum_{s=1}^{S} \mathbf{Z}_{s}^{\prime}\left(\mathbf{X}_{s} \boldsymbol{\Sigma}_{R 1} \mathbf{X}_{s}^{\prime}+\sigma_{R 1}^{2} \mathbf{I}_{n_{s}}\right)^{-1}\left(\ln \left(\mathbf{y}_{s}\right)-\mathbf{X}_{s} \mathbf{b}_{R 1}\right)\right)^{-1} \\
& p\left(\boldsymbol{\beta}_{r s, R 1} \mid \boldsymbol{\beta}_{R 1}, \mathbf{b}_{R 1}, \boldsymbol{\Sigma}_{R 1}, \sigma_{R 1}^{2}, \mathbf{y}, \mathbf{X}, \mathbf{Z}\right)=m v n\left(\boldsymbol{\mu}_{s, R 1}, \mathbf{V}_{s, R 1}\right) \text { where } \\
& \mathbf{V}_{s, R 1}=\left(\boldsymbol{\Sigma}_{R 1}^{-1}+\frac{1}{\sigma_{R 1}^{2}} \mathbf{X}_{S}^{\prime} \mathbf{X}_{s}\right)^{-1} \\
& \boldsymbol{\mu}_{s, R 1}=\mathbf{V}_{s, R 1}\left(\boldsymbol{\Sigma}_{R 1}^{-1} \mathbf{b}_{R 1}+\frac{1}{\sigma_{R 1}^{2}} \mathbf{X}_{s}^{\prime}\left(\ln \left(\mathbf{y}_{s}\right)-\mathbf{Z}_{s} \boldsymbol{\beta}_{R 1}\right)\right) \\
& p\left(\mathbf{b}_{R 1} \mid \boldsymbol{\beta}_{r s, R 1}, \boldsymbol{\Sigma}_{R 1}\right)=\operatorname{mvn}\left(\boldsymbol{\mu}_{b, R 1}, \mathbf{V}_{b, R 1}\right) \text { where } \\
& \mathbf{V}_{b, R 1}=\left(\mathbf{V}_{r}^{-1}+S \Sigma_{R 1}^{-1}\right)^{-1} \\
& \boldsymbol{\mu}_{b, R 1}=\mathbf{V}_{b, R 1}\left(\mathbf{V}_{r}^{-1} \boldsymbol{\mu}_{r}+\boldsymbol{\Sigma}_{R 1}^{-1} \sum_{s=1}^{S} \boldsymbol{\beta}_{r s, R 1}\right) \\
& p\left(\boldsymbol{\Sigma}_{R 1} \mid \boldsymbol{\beta}_{r S, R 1}, \mathbf{b}_{R 1}\right)=i W\left(V_{\sum, R 1}, v_{\sum, R 1}\right) \text { where } \\
& v_{\sum, R 1}=\rho+S \\
& V_{\sum, R 1}=\left(\sum_{s=1}^{S}\left(\boldsymbol{\beta}_{r s, R 1}-\mathbf{b}_{R 1}\right)\left(\boldsymbol{\beta}_{r s, R 1}-\mathbf{b}_{R 1}\right)^{\prime}+\rho R\right) \\
& p\left(\sigma_{R 1}^{2} \mid \boldsymbol{\beta}_{R 1}, \mathbf{b}_{R 1}, \mathbf{y}, \mathbf{X}, \mathbf{Z}\right)=i g\left(\alpha_{R 1}, \gamma_{R 1}\right) \text { where } \\
& \alpha_{R 1}=\frac{1}{2}(n+2 \alpha) \\
& \gamma_{R 1}=\frac{1}{2}\left(\sum_{s=1}^{S}\left(\left(\ln \left(\mathbf{y}_{s}\right)-\mathbf{X}_{s} \boldsymbol{\beta}_{r s, R 1}-\mathbf{Z}_{s} \boldsymbol{\beta}_{R 1}\right)^{\prime}\left(\ln \left(\mathbf{y}_{s}\right)-\mathbf{X}_{s} \boldsymbol{\beta}_{r s, R 1}-\mathbf{Z}_{s} \boldsymbol{\beta}_{R 1}\right)\right)+2 \gamma\right)
\end{aligned}
$$

\section{Appendix B-Literature Search and Database Refinement}

In order to identify relevant SP studies within each risk context, a wide and extensive literature search was conducted. As a starting point, previous meta-analyses and literature overviews on VSL were identified (Braathen et al. 2009; de Blaeij et al. 2003; Kochi et al. 2006; Krupnick 2007; Leggett et al. 2001; Miller 2000; Mrozek and Taylor 2002; Takeuchi 2000; Viscusi and Aldy 2003). From these meta-analyses references to primary studies were obtained based upon two selection criteria; (i) stated preference studies and (ii) cause of death being either environmental or traffic related. Also the references within the primary studies were screened based on the same selection criteria. Following the recommendations by Allen et al. (2006) we do not combine the results from the individual meta-analyses, due to the overlap in included source studies.

The second step consisted of a keyword search in Econlit, Google scholar and EVRI using relevant keywords. These keywords were split up into three categories: (i) method, (ii) 
alternative names for mortality risk and (iii) context specific characteristics. An overview of the keywords used is provided below. Each search included a keyword from each category. Furthermore, we used the "cited by" option in Google scholar to identify new VSL studies.

\begin{tabular}{|c|c|c|}
\hline & Keyword & Alternative keywords \\
\hline 1. Method & $\begin{array}{l}\text { Stated preference } \\
\text { Contingent valuation } \\
\text { Choice experiment } \\
\text { Conjoint (choice) analysis } \\
\text { Willingness to pay }\end{array}$ & $\begin{array}{l}\text { SP, survey, questionnaire } \\
\mathrm{CV}, \mathrm{CVM} \\
\mathrm{CE}, \mathrm{CM} \\
\mathrm{CA} \\
\text { WTP, WTA }\end{array}$ \\
\hline 2. Risk description & $\begin{array}{l}\text { Value of statistical life } \\
\text { Value of prevented } \\
\text { fatality } \\
\text { Statistical value of life } \\
\text { Mortality risk } \\
\text { Risk of dying } \\
\text { Saved lives } \\
\text { Fatal }\end{array}$ & $\begin{array}{l}\text { VSL, VSL } \\
\text { VPF } \\
\text { SVL }\end{array}$ \\
\hline 3. Context & $\begin{array}{l}\text { Air pollution } \\
\text { Contaminated water } \\
\text { Contaminated soil } \\
\text { Environment } \\
\text { Road }\end{array}$ & $\begin{array}{l}\text { Particles, PM, air } \\
\text { quality, sulfates } \\
\text { Water contamination, } \\
\text { arsenic, blue baby } \\
\text { syndrome, drinking } \\
\text { water, water quality, } \\
\text { nitrates } \\
\text { Soil contamination, } \\
\text { superfund, contaminated } \\
\text { ground, waste site } \\
\text { environmental } \\
\text { Traffic, transport, } \\
\text { accident, crash }\end{array}$ \\
\hline
\end{tabular}

The final step in the search procedure consisted of a screening of policy reports in the US (NCEE), UK (e.g. Chilton et al. 2004) and EU (e.g. ExternE 2004). The identified studies were retrieved via internet, library and by contacting individual authors. A copy of Persson and Cedervall (1991) on road safety could not be obtained.

Allen et al. (2006) list the use of same source studies as a potential problem for HW studies. This is also a potential problem in the CV literature. Multiple papers are based on the same underlying survey (e.g. Alberini et al. 2004; Krupnick et al. 2002). To prevent over representation of a single survey and high correlation among observations, we only include a single paper for each survey. As a selection criterion we included the study providing the most extensive description of the risk reduction, but the other papers were also used to obtain general descriptive statistics.

The identified studies can be split up into program choice studies and direct WTP studies. The former category comprises both choice experiments (e.g. Tsuge et al. 2005) and other elicitation approaches (e.g. Carthy et al. 1998) in which respondents value reductions in mortality risk through a series of monetary and non monetary trade-offs. Hence, respondents do not express their WTP for a particular reduction in mortality risk. Direct WTP studies, 
or contingent valuation studies, provide a clear description of the good being valued by the respondent. The focus on a particular risk reduction offers less room for misconception of the concept under consideration compared to the sequence of choices required in program choice studies (Beattie et al. 2000). We therefore only include CV studies. As a consequence several studies had to be excluded from further analysis (e.g. Alberini et al. 2007).

A closer inspection of the environmental context identified that two types of studies were dominating. Most studies focused on WTP for reducing mortality risks caused by air pollution (e.g. Hammitt and Zhou 2006). A second group of studies was designed for applications in environmental policy, but did not explicitly specify a particular cause of death. Its common survey design was developed by Krupnick et al. (1999) and was applied in several countries (US, Canada, France, UK, Italy, Japan, Korea and China). A limited number of studies in the environmental context targeted water pollution (e.g. Carson and Mitchell 2000). The context selection criterion was therefore further refined to including only studies in the air pollution, road safety context; and the context free studies that used the Krupnick et al. (1999) survey design.

The remaining studies were further reviewed regarding the description of the risk reduction, i.e. in the form of a change in the probability of dying, or an equivalent relationship that could be converted into a probabilistic specification. A common analog used to the probability of dying is the number of people saved from a population of a given size (Beattie et al. 1998). This selection criterion resulted in the exclusion of studies valuing mortality risk reductions in the form of increased life expectancy (e.g. Chilton et al. 2004; Desaigues et al. 2007; Johannesson and Johansson 1997). Muller and Reutzel (1984) was excluded due to formulating the probability in dying conditional on the number of crashes instead on the number of people. Further uniformity in the considered mortality risk reductions was achieved by removing studies that valued a reduction in mortality risk and severe injuries at the same time (Andersson and Lindberg 2007; Guria et al. 2003; Hultkrantz et al. 2006). As a consequence all the risk reductions included in the database can be described by a change in the probability of dying of $X$ per 100,000 people to $Y$ per 100,000 people.

The obtained VSL estimates were either based on mean or median WTP values. WTP values are generally heavily skewed to the right, generating a considerable difference between mean and median WTP. Considering the larger number of available mean VSL values we focus our analysis solely on this type. As a result, another nine studies were excluded from further analysis (Adamowicz et al. 2004; Andersson 2007; Cifuentes et al. 2000; Corso et al. 2001; Guo 2006; Hammitt and Graham 1999; Hammitt and Liu 2004; Kim et al. 2003; Dziegielewska and Mendelsohn 2005; Persson et al. 2001; Wang and Mullahy 2006). In accordance we did not register trimmed means, which automatically reduce the VSL due to the skewed distributions.

Alberini and Chiabai (2007) value mortality risk reductions for air pollution and provide 6 distinct values of statistical life for different age and health groups. Since only the respondent characteristics for the overall sample were reported, just a single VSL estimate describing WTP of the average respondent was included in the database. Carlsson et al. (2004) study the effect of different modes of transportation on WTP for mortality risk reductions in the road safety context. For this purpose the authors apply small changes in risk levels resulting in high VSL values. They explicitly highlight that due to these small changes in risk levels their results should not be used for comparison and in public policy. Another exclusion was the study by Bhattacharya et al. (2007) in the road safety context. This study reports an average annual income level of 99,902 dollar (2004 PPP) with a standard deviation of over 93,000 dollar. The reported income level exceeds other income levels by almost a factor 2. Furthermore, preliminary descriptive statistics in the general mortality risk context were 
highly influenced by Ortiz et al. (2004), which was considered and outlier and was therefore excluded. Another exclusions in the general mortality risk context was Giergiczny (2006), because it did not report a baseline risk level from which the change in risk level could be calculated. Language barriers prevented the inclusion of Yamamoto and Oka (1994) in the group of air pollution studies. In the general mortality risk context 2 studies were dropped due to their political sensitivity (Worldbank 2006) and the fact that a final report was not available (Joh et al. 2004).

Hence, the final database consists of 26 valuation studies, 2 for air pollution, 18 for road safety and 6 for general mortality risk studies. Table 1 provides an overview of the studies included in the final database, generating 5 air pollution, 52 road and 20 general mortality VSL estimates.

\section{References}

Adamowicz V, Dupont D, Krupnick A, Srivastava L (2004) Water quality and climate change: what are consumers willing to pay to reduce health risks? http://www.utoronto.ca/envstudy/socioeconomic/english/ Dupont_Final_Nexus_Draft.pdf. Accessed on 16 October 2008

Alberini A (2005) What is a life worth? robustness of VSL values from contingent valuation surveys. Risk Anal 25(4):783-800

Alberini A, Chiabai A (2007) Urban environmental health and sensitive populations: how much are the Italians willing to pay to reduce their risks? Reg Sci Urban Econ 37(2):239-258

Alberini A, Scasny M (2010) Labels and perceptions in mortality risk reduction valuations. Presented at the fourth world congress of environmental and resource economics, Montreal, Canada

Alberini A, Cropper M, Krupnick A, Simon NB (2004) Does the value of a statistical life vary with age and health status? Evidence from the US and Canada. J Environ Econ Manage 48(1):769-792

Alberini A, Scasny M, Kohlova MB, Melichar J (2005) The value of a statistical life in the Czech Republic: evidence from a contingent valuation study. In: Menne B, Ebi KL (eds) Climate change and adaptation strategies for human health. Springer, Darmstadt pp 373-393

Alberini A, Tonin S, Turvani M, Chiabai A (2007) Paying for permanence: public preferences for contaminated site cleanup. J Risk Uncertain 34(2):155-178

Allen E, Becker BJ, Berlin JA, Morton SC, Olkin I, Rindskopf D, Sampson AR, Wilson DR (2006) Report of the EPA work group on VSL meta-analyses. US Environmental Protection Agency EE-0494-01. http:// yosemite.epa.gov/ee/epa/eermfile.nsf/vwAN/EE-0494-01.pdf/\$File/EE-0494-01.pdf. Accessed on 16 October 2008

Andersson H (2007) Willingness to pay for road safety and estimates of the risk of death: evidence from a Swedish contingent valuation study. Accid Anal Prevent 39(4):853-865

Andersson H, Lindberg G (2007) Benevolence and the value of road safety. http://www.vti.se/EPiBrowser/ hosting/Andersson_Lindberg_Benevolence.pdf. Accessed on 16 October 2008

Andersson H, Svensson M (2008) Cognitive ability and scale bias in the contingent valuation method. Environ Resour Econ 39(4):481-495

Bateman IJ, Langford IH, Turner RK, Willis KG, Garrod GD (1995) Elicitation and truncation effects in contingent valuation studies. Ecol Econ 12(2):161-179

Beattie J, Carthy T, Chilton S, Covey J, Dolan P, Hopkins L, Jones-Lee MW, Loomes G, Pidgeon N, Robinson A, Spencer A (2000) Valuation of benefits of health and safety control: summary and technical report. Health and Safety Executive CRR 273/2000

Beattie J, Covey J, Dolan P, Hopkins L, Jones-Lee M, Loomes G, Pidgeon N, Robinson A, Spencer A (1998) On the contingent valuation of safety and the safety of contingent valuation: part 1-caveat investigator. J Risk Uncertain 17(1):5-26

Bhattacharya S, Alberini A, Cropper M (2007) The value of mortality risk reductions in Delhi, India. J Risk Uncertain 34(1):21-47

Braathen NA, Lindhjem H, Navrud S (2009) Valuing lives saved from environmental, transport and health policies: a meta-analysis of stated preference studies. Presented at the EAERE conference 2009 in Amsterdam

Brouwer R (2000) Environmental value transfer: state of the art and future prospects. Ecol Econ 32(1): $137-152$ 
Carlsson F, Johansson-Stenman O, Martinsson P (2004) Is transport safety more valuable in the air? J Risk Uncertain 28(2):147-163

Carson RT, Flores NE, Meade NF (2001) Contingent valuation: controversies and evidence. Environ Resour Econ 19(2):173-210

Carson RT, Groves T (2007) Incentive and informational properties of preference questions. Environ Resour Econ 37(1):181-210

Carson RT, Mitchell RC (2000) Public preferences toward environmental risks: the case of trihalomethanes. ftp://weber.ucsd.edu/pub/econlib/dpapers/2000-21.pdf. Accessed on 16 October 2008

Carthy T, Chilton S, Covey J, Hopkins L, Jones-Lee M, Loomes G, Pidgeon N, Spencer A (1998) On the contingent valuation of safety and the safety of contingent valuation: part 2-The CV/SG "Chained" approach. J Risk Uncertain 17(3):187-214

Chestnut LG, Rowe RD, Lazo JK, Breffle WS (2004) Economic valuation of mortality risk reduction: vol I; a stated preference approach. US EPA C.R. 824393-01-0

Chib S (1995) Marginal likelihood from the Gibbs output. J Am Stat Assoc 90(432):1313-1321

Chilton S, Covey J, Hopkins L, Jones-Lee M, Loomes G, Pidgeon N, Spencer A (2002) Public perceptions of risk and preference-based values of safety. J Risk Uncertain 25(3):211-232

Chilton S, Covey J, Jones-Lee MW, Loomes G, Metcalf H (2004) Valuation of health benefits associated with reductions in air pollution DEFRA. http://www.defra.gov.uk/environment/airquality/publications/ healthbenefits/airpollution_reduction.pdf. Accessed on 16 October 2008

Cifuentes LA, Prieto JJ, Escobari J (2000) Valuing mortality risk reductions at present and at advanced age: preliminary results from a contingent valuation study in Chile. http://www.luiscifuentes.cl/Docs/ PaperCVCifuentes-Prieto-Escobari.pdf. Accessed on 16 October 2008

Collins JP, Vossler CA (2009) Incentive compatibility tests of choice experiment value elicitation questions. J Environ Econ Manage 58(2):226-235

Cookson R (2000) Incorporating psycho-social considerations into health valuation: an experimental study. J Health Econ 19(3):369-401

Corso PS, Hammitt JK, Graham JD (2001) Valuing mortality-risk reduction: using visual aids to improve the validity of contingent valuation. J Risk Uncertain 23(2):165-184

Covey J (2002) People's preferences for safety control: why does baseline risk matter? Risk Anal 21(2): $331-340$

de Blaeij A, Florax RJGM, Rietveld P, Verhoef E (2003) The value of statistical life in road safety: a metaanalysis. Accid Anal Prevent 35(6):973-986

de Brabander B (2006) De waardering van dodelijke verkeersslachtoffers in Vlaanderen: resultaten van contingente waardering. Steunpunt beleidsrelevant onderzoek verkeersveiligheid 2007-111. http://www. steunpuntmowverkeersveiligheid.be/modules/publications/store/135.pdf. Accessed on 16 October 2008

Desaigues B, Rabl A (1995) Reference values for human life: an econometric analysis of a contingent valuation in France. In: Schwab Christe NG, Soguel NC (eds) Contingent valuation, transport safety and the value of life. Springer, London pp 85-112

Desaigues B, Rabl A, Chilton S, Metcalf H, Hunt A, Ortiz RA, Navrud S (2007) Final report on the monetary valuation of mortality and morbidity risks from air pollution. NEEDS 6.7-RS $1 \mathrm{~b}$

DeShazo JR, Cameron TA (2005) Mortality and morbidity risk reduction: an empirical life-cycle model of demand with two types of age effects. http://faculty.spa.ucla.edu/deshazo/pdf/14/Age_paper_allparts. pdf. Accessed on 16 October 2008

Dockins C, Maguire K, Simon N, Sullivan M (2004) Value of statistical life analysis and environmental policy: a white paper. US Environmental Protection Agency EE-0483-01. http://yosemite.epa.gov/ee/epa/ eermfile.nsf/vwAN/EE-0483-01.pdf/\$File/EE-0483-01.pdf. Accessed on 16 October 2008

Dunn H (2001) UK perspective on valuing mortality risk in the air pollution context. http://earth2.epa.gov/ ncer/publications/workshop/pdf/EE-0464-02.pdf. Accessed on 16 October 2008

Dziegielewska PDA, Mendelsohn R (2005) Valuing air quality in Poland. Environ Resour Econ 30(2): $131-163$

Elvik R (1995) An analysis of official economic valuations of traffic accident fatalities in 20 motorized countries. Accid Anal Prevent 27(2):237-247

Evans MF, Smith VK (2006) Do we really understand the age-VSL relationship? Resour Energy Econ 28(3):242-261

ExternE (2004) New elements for the assessment of external costs from energy technologies. Final Report to the European Commission, DG Research, Technological Development and Demonstration (RTD). http:// www.ier.uni-stuttgart.de/forschung/projektwebsites/newext/newext_final.pdf. Accessed on 16 October 2008

Gelman A, Carlin JB, Stern HS, Rubin DB (2004) Bayesian data analysis. Chapman and Hall, London 
Geweke J (1992) Evaluating the accuracy of sampling-based approaches to the calculation of posterior moments. In: Bernardo J et al (ed) Bayesian statistics 4. Clarendon Press, Oxford pp 641-649

Ghani N, Faudzi M (2003) Value of life of Malaysian motorists: estimates from a nation wide survey. http:// www.easts.info/2003journal/papers/3031.pdf. Accessed on 16 October 2008

Giergiczny M (2006) Value of statistical life-case of Poland. Presented at the 3rd Annual Congress of Association of Environmental and Resource Economics AERE in Kyoto

Guo X (2006) The economic value of air-pollution-related health risks in China. Ohio State University. http:// www.ohiolink.edu/etd/send-pdf.cgi/Guo\%20Xiaoqi.pdf?acc_num=osu1155652414. Accessed 16 October 2008

Guria J, Jones W, Jones-Lee MW, Keal M, Leung J, Loomes G (2003) The New Zealand values of statistical life and of the prevention of injuries. Land Transport Safety Authority

Guria J, Leung J, Jones-Lee M, Loomes G (2005) The willingness to accept value of statistical life relative to the willingness to pay value: evidence and policy implications. Environ Resour Econ 32(1):113-127

Hakes JH, Viscusi WK (2007) Automobile Seatbelt usage and the value of statistical life. Southern Econ J 73(3):659

Hammitt J, Zhou Y (2006) The economic value of air-pollution-related health risks in China: a contingent valuation study. Environ Resour Econ 33(3):399-423

Hammitt JK, Graham JD (1999) Willingness to pay for health protection: inadequate sensitivity to probability? J Risk Uncertain 18(1):33-62

Hammitt JK, Liu JT (2004) Effects of disease type and latency on the value of mortality risk. J Risk Uncertain 28(1):73-95

Hultkrantz L, Lindberg G, Andersson C (2006) The value of improved road safety. J Risk Uncertain 32(2): 151-170

Itaoka K, Krupnick A, Akai M, Alberini A, Cropper M, Simon N (2005) Age, Health and the willingness to pay for mortality risk reductions: A contingent valuation survey in Japan. Resources For the future discussion paper 05-34. http://www.rff.org/documents/RFF-DP-05-34.pdf. Accessed on 16 October 2008

Joh S, Nam YM, Shim S, Sung J, Shin Y (2004) Empirical study of environmental ancillary benefits due to greenhouse gas mitigation in Korea. Int J Sust Develop 6(-): 311-327

Johannesson M, Johansson PO (1997) Quality of life and the WTP for an increased life expectancy at an advanced age. J Public Econ 65(2):219-228

Johannesson M, Johansson PO, O'Conor RM (1996) The value of private safety versus the value of public safety. J Risk Uncertain 13(3):263-275

Johnston RJ, Duke JM (2009) Willingness to pay for land preservation across states and jurisdictional scale: implications for benefit transfer. Land Econ 85(2):217-237

Johnston RJ, Ranshon MW, Besedin EY, Helm EC (2006) What determines willingness to pay per fish? A meta-analysis of recreational fishing values. Marine Resour Econ 21:1-32

Jones-Lee MW, Hammerton M, Philips PR (1983) The value of safety: results of a national sample survey. Econ J 95(377):49-72

Kass RE, Raftery AE (1995) Bayes factors. J Am Stat Assoc 90(430):773-795

Kidholm K (1995) Assessing the value of traffic safety using the contingent valuation technique: the Danish survey. In: Schwab Christe NG, Soguel NC (eds) Contingent valuation, transport safety and the value of life. Springer, London pp 45-62

Kim YS, Lee YJ, Park HS, Shin DC (2003) Risk-based damage cost estimation on mortality due to environmental problems. Korean J Prev Med 36(3):230-238

Kochi I, Hubbell B, Kramer R (2006) An empirical Bayes approach to combining and comparing estimates of the value of a statistical life for environmental policy analysis. Environ Resour Econ 34(3):385-406

Krupnick A (2007) Mortality-risk valuation and age: stated preference evidence. Rev Environ Econ Policy 1(2):261-282

Krupnick A, Alberini A, Cropper M, Simon N (1999) Mortality risk valuation for environmental policy. Resources For the Future 99-47. http://www.rff.org/rff/Documents/RFF-DP-99-47.pdf. Accessed on 16 October 2008

Krupnick A, Alberini A, Cropper M, Simon N, O’Brien B, Goeree R, Heintzelman M (2002) Age, health and the willingness to pay for mortality risk reductions: a contingent valuation survey of Ontario residents. J Risk Uncertain 24(2):161-186

Lanoie P, Pedro C, Latour R (1995) The value of a statistical life: a comparison of two approaches. J Risk Uncertain 10(3):235-257

Leggett CG, Penumalli PR, Neumann JE (2001) Willingness to pay for reductions in fatal risk: a meta-analysis of the value of statistical life literature. http://es.epa.gov/ncer/publications/workshop/pdf/EE-0464-03. pdf\#page $=53$. Accessed on 16 October 2008 
Maier G, Gerking S, Weiss P (1989) The economics of traffic accidents on Austrian roads: risk lovers or policy deficit? Empirica 16(2):177-192

McDaniels TL (1992) Reference points, loss aversion, and contingent values for auto safety. J Risk Uncertain 5(2): $187-200$

McDaniels TL, Kamlet MS, Fischer GW (1992) Risk perception and the value of safety. Risk Analysis 12(4):495-503

Miller TR (2000) Variations between countries in value of statistical life. J Transport Econ Policy 34(2): 169-188

Miller TR, Guria J (1991) The value of statistical life in New Zealand. Land Transport Division, Ministry of Transport

Moeltner K, Boyle KJ, Paterson RW (2007) Meta-analysis and benefit transfer for resource valuation-addressing classical challenges with Bayesian modeling. J Envir Econ Manage 53(2):250-269

Moeltner K, Woodward R (2009) Meta-functional benefit transfer for Wetland valuation: making the most of small samples. Environ Resour Econ 42(1):89-109

Mrozek JR, Taylor LO (2002) What determines the value of life? a meta-analysis. J Policy Anal Manage 21(2):253-270

Muller A, Reutzel TJ (1984) Willingness to pay for reduction in fatality risk: an exploratory survey. Am J Public Health 74(8):808-812

Navrud S, Ready R (2007) Review of methods for value transfer. In: Navrud S, Ready REnvironmental value transfer: issues and methods. Springer, Dordrecht, The Netherlands

Ortiz RA, Markandya A, Hunt A (2004) Willingness to pay for reduction in immediate risk of mortality related to air pollution in Sao Paulo, Brazil. http://www.oecd.org/dataoecd/2/7/37585517.pdf. Accessed on 16 October 2008

Persson U, Cedervall M (1991) The value of risk reduction: results from a Swedish sample survey

Persson U, Lugner Norinder A, Svensson M (1995) Valuing the benefits of reducing the risk of non-fatal road injuries: the Swedish experience. In: Schwab Christe NG, Soguel NC (eds) Contingent valuation, transport safety and the value of life. pp 63-83

Persson U, Norinder A, Hjalte K, Gralen K (2001) The value of a statistical life in transport: findings from a new contingent valuation study in Sweden. J Risk Uncertain 23(2):121-134

Pratt JW, Zeckhauser RJ (1996) Willingness to pay and the distribution of risk and wealth. J Political Economy 104(4):747-763

Revesz RL (1999) Environmental regulation, cost benefit analysis, and the discounting of human lives. Columbia Law Rev 99(4):941-1017

Rosenberger RS, Stanly TD (2006) Measurement, generalization, and publication: sources of error in benefit transfers and their management. Ecol Econ 60(2):372-378

Rothstein HR, Sutton AJ, Borenstein M (2005) Publication in meta-analysis assessment and adjustments. John Wiley and Sons, Sussex

Rowlatt P, Spackman M, Jones S, Jones-Lee M, Loomes G (1998) Valuation of deaths from air pollution. National Economic Research Associates http://www.nera.com/image/3884.pdf. Accessed on 16 October 2008

Savage L (1993) An empirical investigation into the effect of psychological perceptions on the willingnessto-pay to reduce risk. J Risk Uncertain 6(1):75-90

Schwab Christe NG (1995) The valuation of human costs by the contingent method: the Swiss experience. In: Schwab Christe NG, Soguel NC (eds) Contingent valuation, transport safety and the value of life, pp 19-43

Schwab Christe NG, Soguel NC (1995) Contingent valuation, transport safety and the value of life. Kluwer Academic Publishers Group

Schwab Christe NG, Soguel NC (1996) The pain of road-accident victims and the bereavement of their relatives: a contingent-valuation experiment. J Risk Uncertain 13(3):277-291

Slovic P (1987) Perception of risk. Science 236(4799):280-285

Slovic P (2000) The perception of risk. Earthscan, London

Smith V, Pattanayak S (2002) Is meta-analysis a Noah's ark for non-market valuation? Environ Resour Econ 22(1):271-296

Strand J (2001) Public- and private-good values of statistical lives: results from a combined choice-experiment and contingent-valuation survey. http://folk.uio.no/jostrand/lifepaper02.pdf. Accessed on 16 October 2008

Subramanian U, Cropper M (2000) Public choices between life saving programs: the tradeoff between qualitative factors and lives saved. J Risk Uncertain 21(1):117-149

Sunstein CR (2004) Value of life: a plea for disaggregation. Duke Law J 54:385-444 
Takeuchi K (2000) A meta-analysis of the value of statistical life. Institute of Social Sciences Meiji University F-2000-2

Tsuge T, Kishimoto A, Takeuchi K (2005) A choice experiment approach to the valuation of mortality. J Risk Uncertain 31(1):73-95

US EPA (2000) Guidelines for preparing economic analyses. EPA 240-R-00-003. http://yosemite.epa.gov/ee/ epa/eed.nsf/webpages/Guidelines.html/\$file/Guidelines.pdf. Accessed on 16 October 2008

Vassanadumrongdee S, Matsuoka S (2005) Risk perceptions and value of a statistical life for air pollution and traffic accidents: evidence from Bangkok, Thailand. J Risk Uncertain 30(3):261-287

Viscusi WK, Aldy JE (2003) The value of a statistical life: a critical review of market estimates throughout the world. J Risk Uncertain 27(1):5-76

Viscusi WK, Magat WA, Huber J (1991) Pricing environmental health risks: survey assessments of risk—risk and risk-dollar trade-offs for chronic bronchitis. J Environ Econ Manage 21(1):32-51

Wang H, Mullahy J (2006) Willingness to pay for reducing fatal risk by improving air quality: a contingent valuation study in Chongqing, China. Sci Total Environ 367(1):50-57

Worldbank (2006) Valuation of environmental health risks. In: Cost of pollution in China: economic estimates of physical damages. Worldbank, Bejing, pp 67-78

Yamamoto S, Oka T (1994) The value of a statistical life of Japanese people: an estimate from a survey on the willingness to pay for reducing a health risk of drinking water. Environ Sci 7:289-300 